\section{Einladung Landesversammlung Sachsen}

am Sonnabend, den 23. April 2016, 9.30 Uhr, im Mercure Hotel, Stephanstr. 6, 04103 Leipzig

\section{Tagesordnung}

1. Eröffnung der Landesversammlung durch den Versammlungsleiter Herrn Dr. Beyer

2. Begrüßung durch den Landesvorsitzenden, Herrn Dr. Tischendorf

3. Vortrag „Datenschutz in der Zahnarztpraxis: Rechtliche Folgen der zunehmenden Vernetzung“"

Referent: Dr. Bernhard Freund, Rechtsanwalt aus Hamburg

Dr. Bernhard Freund ist Hamburger Rechtsanwalt, Informatiker und Sachverständiger beim Unabhängigen Landeszentrum für Datenschutz Schleswig-Holstein. Als Partner der Kanzlei PLANIT // LEGAL berät er in den Bereichen Datenschutz- und IT-Recht. Vor Gründung der eigenen Kanzlei mit zwei Kollegen war RA Dr. Freund unter anderem Referent bei der Datenschutzaufsichtsbehörde in Hamburg.

\section{Bericht des Landesvorsitzenden \\ 5. Anträge und Beschlussfassung \\ 6. Bericht der Kassenprüfer über das Geschäftsjahr 2015 \\ 7. Entlastung des Landesvorstands \\ 8. Haushaltsplan 2016}

Der Vorstand des Landesverbands Sachsen lädt hiermit gemäß $\$ 14$ der Satzung seine stimmberechtigten Mitglieder zur Landesversammlung 2016 ein. Darüber hinaus sind alle Mitglieder des Freien Verbands Deutscher Zahnärzte e. V. sehr herzlich eingeladen (bitte Anmeldung über die Landesgeschäftsstelle Tel. 0341/ 96021 39, Fax 0341/ 9602140 oder per E-Mail: fvdz.lvsachsen@teleson-mail.de).

Anträge und Beschlussvorlagen sind spätestens zwei Wochen vor der Landesversammlung über die Geschäftsstelle schriftlich einzureichen und zu begründen.

Ende der Landesversammlung etwa 12.30 Uhr.

\section{Mit freundlichen Grüßen}

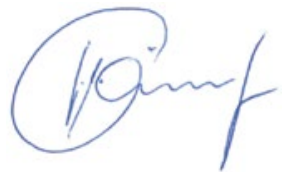

Dr. Uwe Tischendorf Landesvorsitzender

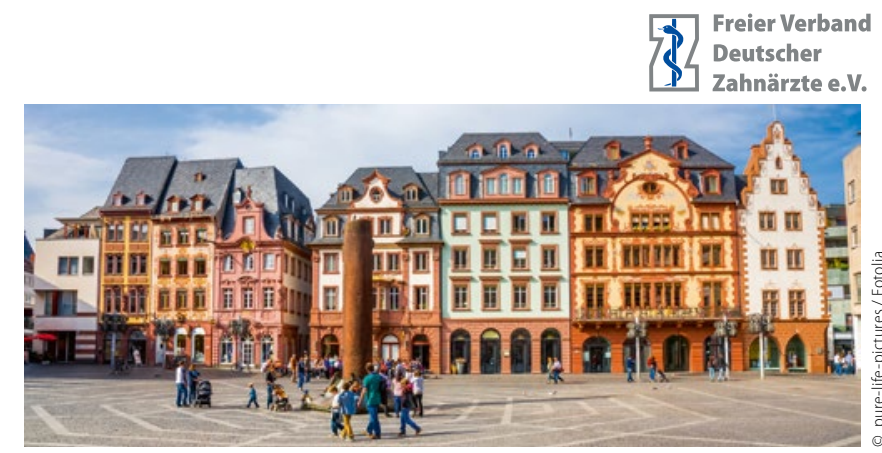

Einladung

Landesversammlung Rheinland-Pfalz

Ort: Novotel Mainz, 55131 Mainz, Augustusstr. 6

Termin: Samstag, den 23.April 2016, 09.30 Uhr

\section{Tagesordnung}

1. Eröffnung durch den Versammlungsleiter

2. Begrüßung durch die Landesvorsitzende, Ehrungen langjähriger Mitglieder

3. Bericht der Landesvorsitzenden

4. Vortrag mit anschließender Diskussion:

„Unter Strom und ständig online - Unser Gehirn heute zwischen Reizflut und Multitasking“

Gastreferent: Priv.-Doz.Dr.med.habil. Volker Busch, Oberarzt Facharzt für Neurologie

Facharzt für Psychiatrie und Psychotherapie

Leiter wissenschaft. AG Psychosozialer Stress und Schmerz 93053 Klinik für Psychiatrie und Psychotherapie der Universität Regensburg

\section{Mittagspause}
5. Bericht zur Lage des Landesverbands
6. Bericht des Kassenprüfers
7. Entlastung des Landesvorstands
8. Wahl des Landesvorstands
9. Haushaltsplan
9. Anträge
10. Aussprache

Der Landesvorstand Rheinland-Pfalz lädt hiermit gemäß $\$ 14$ Abs. 2-6 der Satzung seine stimmberechtigten Mitglieder zur Landesversammlung 2016 ein; ebenso sind alle Kolleginnen und Kollegen aus Rheinland-Pfalz zum öffentlichen Teil der Veranstaltung gern gesehene Gäste. Anträge sind bis spätestens zwei Wochen vor der Landesversammlung über die Landesgeschäftsstelle schriftlich einzureichen und zu begründen.

Mit kollegialen Grüßen

Dr. Ulrike Stern

Landesvorsitzende 